\title{
Phylogenetic study and barcoding of the blood cockle, Tegillarca granosa, found on the west coast of peninsular Malaysia using the COI gene
}

\author{
S.Y. Chee' ${ }^{1}$, M.N. Devakie ${ }^{2}$ and M.N. Siti Azizah ${ }^{1}$ \\ ${ }^{1}$ School of Biological Sciences, Universiti Sains Malaysia, Penang, Malaysia \\ ${ }^{2}$ Fisheries Research Institute, Batu Maung, Penang, Malaysia \\ Corresponding author: S.Y. Chee \\ E-mail: suyinchee@gmail.com
}

Genet. Mol. Res. 10 (2): 1237-1244 (2011)

Received October 14, 2010

Accepted December 10, 2010

Published June 28, 2011

DOI 10.4238/vol10-2gmr1104

\begin{abstract}
Blood cockles are among the most economically important brackish water invertebrates found in Malaysia. However, our knowledge of blood cockle phylogeny and systematics is rudimentary, especially for the species Tegillarca granosa. It is unclear, for instance, whether the cockles occurring on the west coast of peninsular Malaysia constitute a single species, or multiple, phylogenetically distinct species. We performed the first DNA molecular phylogenetic analysis of T. granosa to distinguish it from other related species found in other parts of the world and to create a DNA database for the species. An approximately 585-nucleotide fragment of the mitochondrial DNA (cytochrome oxidase I, COI) was sequenced for 150 individual cockles, representing 10 populations: three from the north, four from the central part and three from the southern part of peninsular Malaysia. Phylogenetic analyses of the resulting dataset yielded tree topologies that not only showed the relationship between $T$. granosa and its closest relatives but its position in the evolutionary tree. Three mitochondrial clades were evident, each containing an individual genus. Using the
\end{abstract}


mutation rate of the COI gene, the divergence time between $T$. granosa and its closest related species was estimated to be 460 thousand years ago. This study provides a phylogenetic framework for this ecologically prominent and commercially important cockle species.

Key words: Tegillarca granosa; Phylogenetic analysis; COI

\section{INTRODUCTION}

The blood cockle, Tegillarca granosa, an arcid bivalve mollusc, is an important marine product in Malaysia. Blood cockles are benthic organisms with a sessile adult stage and a pelagic larval stage (Pathansali, 1963). Their distributions depend heavily on the salinity of the water and are found most commonly under brackish sand and fine, soft, mud bottoms (Pathansali and Soong, 1958; Pathansali, 1963). In 1984, about 65,000 tons of cockles were produced from cultured stocks, making it the most important aquaculture industry in Malaysia (Ng, 1986). In 1986, cockle culture accounted for about 11\% of the country's total fisheries production $(\mathrm{Ng}, 1986)$. Malaysia's output of blood cockles was ranked 5th in Asia and Pacific with 78,712 tons in 2002, in the top 10 producers of lower value molluscs (Sugiyama et al., 2004) contributing to the total export of US $\$ 525,546,000$ worth of fishery products (Pawiro, 2006). In the year 2006, 4000 to 5000 hectares of the west coast of Peninsular Malaysia were used for cockle culture (FAO, 2006).

While many molecular markers have been discovered for a wide range of bivalves globally, there are still species of economic significance that have received little attention, such as $T$. granosa. Like most invertebrates, the larval dispersal patterns of the cockles are poorly understood (Banks et al., 2006). Origins of naturally recruited spat of this cockle species are unknown, as is the impact of translocations and natural population structure. Thus, the cytochrome oxidase I (COI) gene was investigated in this phylogenetic study using primers designed for bivalves of the same genus. The application of molecular methods to questions of blood cockle phylogeny and systematics has provided valuable new insights into blood cockle evolutionary relationships and has allowed independent testing of preexisting hypotheses.

Our primary goal in this study was to find out the position of the T. granosa in the evolutionary tree utilizing approximately $585 \mathrm{bp}$ of the mitochondrial COI gene. A phylogenetic framework for the blood cockles is needed in order for cockles to survive the effects of water pollution common on the west coast of Peninsular Malaysia, introduction of exotic species and negative effects of aquaculture. It is also needed to replace organism classification based on morphological characteristics, which are known to be inaccurate and unreliable (Doadrio and Dominguez, 2004). Proper classification and identification of T. granosa will help ensure effective management of the species in aquaculture and in the wild.

\section{MATERIAL AND METHODS}

Specimens from the west coast of Peninsular Malaysia were collected in collaboration with the Fisheries Research Institute (FRI) (Figure 1). All cockles were collected one nautical mile away from the coastline using a core. A total of 150 individuals from 10 populations collected from Kedah, Penang, Perak, Selangor, and Johor were used in this experiment. Table 1 
shows the coordinates of the sites at which the cockles were collected.

First, mantle tissue was dissected from the cockle and stored in TNES-urea (180 g urea, $1 \mathrm{M}$ Tris-HCl, pH 7.5, 0.2 M EDTA, 10\% SDS) for subsequent DNA extraction and amplification. Genomic DNA was extracted from $100 \mu \mathrm{L}$ TNES-tissue mixture using the AQUAGENOMIC ${ }^{\mathrm{TM}}$ kit procedure. The quality and concentration of DNA from samples were assessed on $0.8 \%$ agarose gel electrophoresis and spectrophotometric analysis. The samples were then stored at $4^{\circ} \mathrm{C}$ until used.

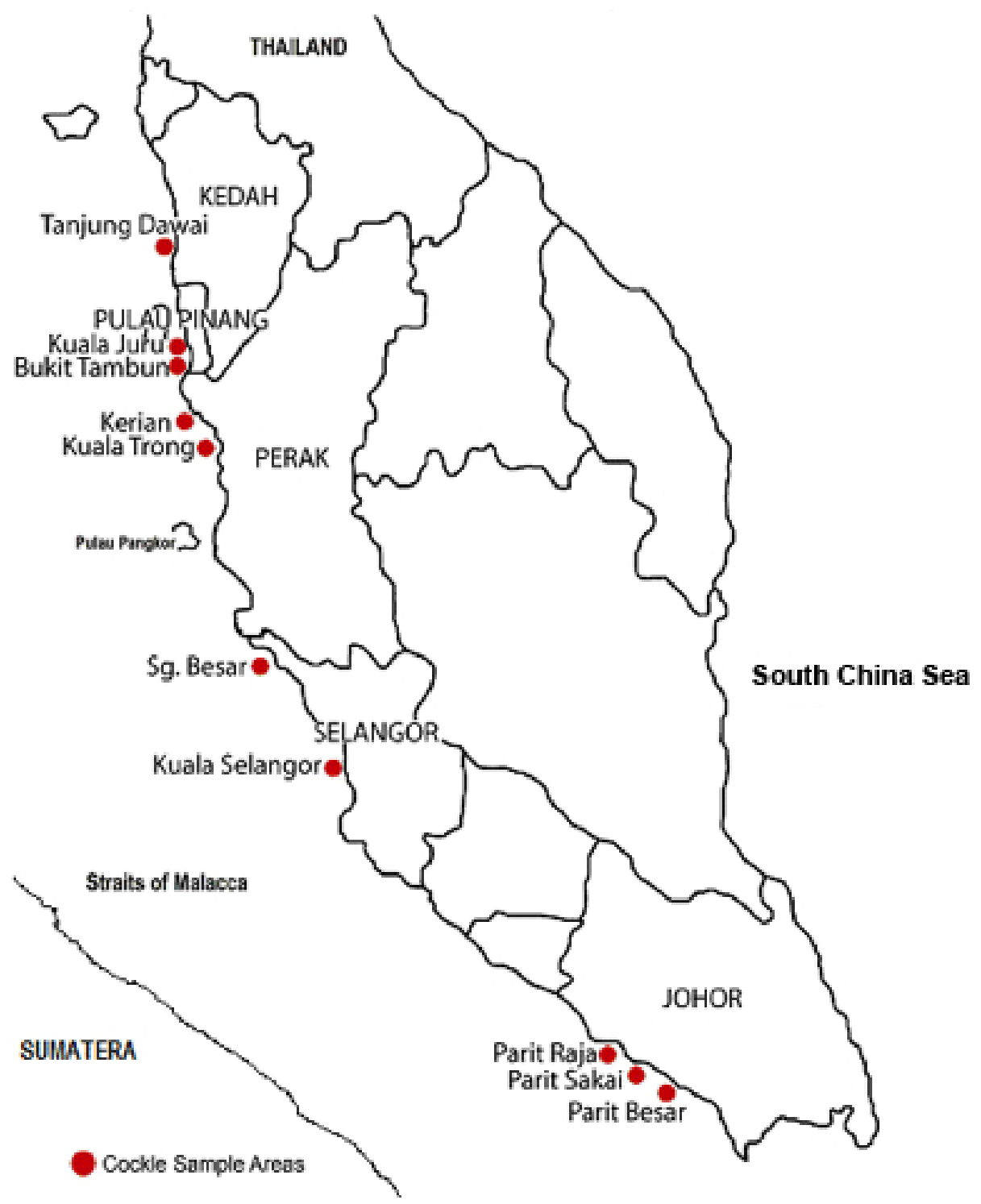

Figure 1. Tegillarca granosa sample areas in Peninsular Malaysia. 
Table 1. Coordinates of sites at which cockles were obtained.

\begin{tabular}{|c|c|}
\hline Sampling site & Coordinates \\
\hline Tanjung Dawai (Kedah) & $5^{\circ} 40^{\prime} 43.28^{\prime \prime} \mathrm{N}, 100^{\circ} 20^{\prime} 23.24^{\prime \prime} \mathrm{E}$ \\
\hline Kuala Juru (Penang) & $5^{\circ} 19^{\prime} 59.944^{\prime \prime} \mathrm{N}, 100^{\circ} 23^{\prime} 55.34{ }^{\prime \prime} \mathrm{E}$ \\
\hline Bukit Tambun (Penang) & $5^{\circ} 16^{\prime} 44.02^{\prime \prime} \mathrm{N}, 100^{\circ} 24^{\prime} 27.00^{\prime \prime} \mathrm{E}$ \\
\hline Kerian (Perak)a & $4^{\circ} 57^{\prime} 56.10^{\prime \prime} \mathrm{N}, 100^{\circ} 23^{\prime} 49.14^{\prime \prime} \mathrm{E}$ \\
\hline Kuala Trong (Perak) & $4^{\circ} 38^{\prime} 45.49^{\prime \prime} \mathrm{N}, 100^{\circ} 33^{\prime} 54.45^{\prime \prime} \mathrm{E}$ \\
\hline Sungai Besar (Selangor) & $3^{\circ} 49^{\prime} 20.94 ’ \mathrm{~N}, 100^{\circ} 47^{\prime} 07.93^{\prime \prime} \mathrm{E}$ \\
\hline Kuala Selangor (Selangor) & $3^{\circ} 19^{\prime} 37.02^{\prime \prime} \mathrm{N}, 101^{\circ} 13^{\prime} 25.85^{\prime \prime} \mathrm{E}$ \\
\hline Parit Raja (Johor) & $1^{\circ} 47^{\prime} 57.48^{\prime \prime} \mathrm{N}, 102^{\circ} 52^{\prime} 37.83^{\prime \prime} \mathrm{E}$ \\
\hline Parit Sakai (Johor) & $1^{\circ} 44^{\prime} 46.93$ 'N, $102^{\circ} 55^{\prime} 22.95$ 'E \\
\hline Parit Besar (Johor) & $1^{\circ} 43^{\prime} 23.99 " \mathrm{~N}, 103^{\circ} 00^{\prime} 49.09^{\prime \prime} \mathrm{E}$ \\
\hline
\end{tabular}

DNA amplification was done in a volume of $25 \mu \mathrm{L}$, containing $2.5 \mu \mathrm{L} 10 \mathrm{X}$ PCR buffer (Bioron), $0.5 \mu \mathrm{L} 10 \mathrm{mM}$ deoxynucleotide (dNTP), $0.75 \mu \mathrm{L} 100 \mathrm{mM} \mathrm{MgCl}, 0.8 \mu \mathrm{L}$ of each forward (5'-CWA-ATC-AYA-AAG-ATA-TTG-GAA-C-3') and reverse (5'-AAT-ATAWAC-TTC-WGG-GTG-ACC-3') primer, $0.3 \mu \mathrm{L} 5 \mathrm{U}$ Taq-polymerase (Bioron) and $1.5 \mu \mathrm{L}$ template DNA. Amplifications were performed in a PTC-200 Peltier thermocycler, which was programmed for 31 cycles: $30 \mathrm{~s}$ at $95^{\circ} \mathrm{C}, 45 \mathrm{~s}$ at $43^{\circ} \mathrm{C}$ and $1 \mathrm{~min}$ at $72^{\circ} \mathrm{C}$ (Colgan et al., 2003). A volume of $8 \mu \mathrm{L}$ of each reaction product was separated by electrophoresis on $1.5 \%$ agarose TBE (Tris-borate EDTA) gels at $90 \mathrm{~V}$ for $2 \mathrm{~h}$. A 100-bp plus ladder was used as a molecular ruler. The products were stained with ethidium bromide and observed under UV light.

The DNA fragment that represents the COI gene was excised with a clean, sharp scalpel. The excised gel was then purified using EZ-10 Spin Column DNA Gel Extraction Kit (Bio Basic Inc.). At the end of the purification process, $30 \mu \mathrm{L}$ of product was eluted. The recovery yields using this kit are approximately $60-80 \%$. An $8-\mu \mathrm{L}$ aliquot of the total eluate was used to load a $1.5 \%$ agarose TBE gel. The quality of the purified product was confirmed by the brightness and specificity of the band before it was prepared and sent for sequencing. Good sequences were aligned using the MEGA 4 software (Tamura et al., 2007). All 150 sequences were then collapsed in haplotypes using the Collapse software (version 1.2; Provan et al., 2005). The partial COI gene of T. granosa was then "blasted" with the COI gene of other species from the same genus using blastn from GenBank.

All sequences (T. granosa and other bivalves from the same family obtained from GenBank) were aligned and a dendrogram was built to depict the phylogeographic relationship using a distance tree of pairwise comparisons provided by NCBI.

\section{RESULTS}

A 585-bp segment of the COI gene of T. granosa from Malaysia was sequenced (Figure 2). Collapsing the 150 sequences yielded 22 haplotypes, which were then submitted to GenBank. Accession numbers obtained from GenBank for the sequences were: FJ411459, FJ411460, FJ411462, FJ411470, FJ411471, FJ411473, FJ411474, FJ411477, FJ411479, and FJ411480. The T. granosa sequences had a maximum identity of $98-99 \%$ with each other. The sequences also had $77 \%$ maximum identity with the COI gene of Anadara grandis (603 bp) from Colombia, 75\% with A. tuberculosa (603 bp) from Costa 


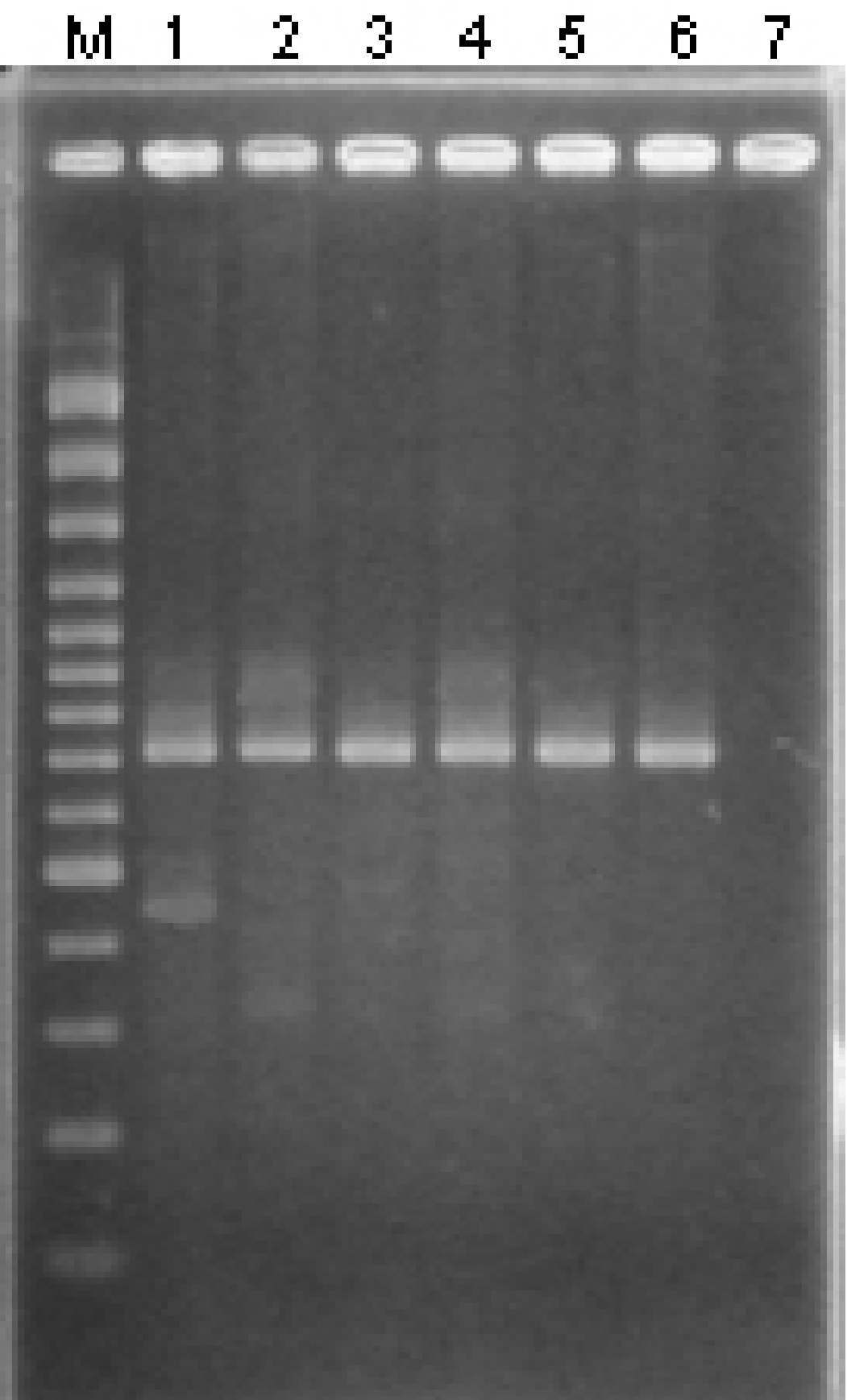

Figure 2. The single fragment of the COI gene (585 bp) as amplified by PCR against a 100-bp DNA Ladder Plus Lane $M=$ marker $100 \mathrm{bp}+$; lanes 1 to $6=$ Tegillarca granosa samples; lane $7=$ negative control. 
Rica, 75\% with $A$. similis (603 bp) from Ecuador, 75\% with $A$. adamsi and $A$. nux (both $586 \mathrm{bp}$ ) from Panama, $75 \%$ with $A$. trapezia (580 bp) from Queensland, $75 \%$ with $A$. ovalis (586 bp) from Florida, 73\% with $A$. chemnitzii (586 bp) from Costa Rica, and 73\% with A. transversa $(570 \mathrm{bp}$ ) from Florida over the average query coverage of $86 \%$ (Figure 3 ). Tegillarca granosa is the only cockle among the other mentioned species found in South East Asia, whereas the majority are found in Northeast Australia, Central America and the Caribbean.

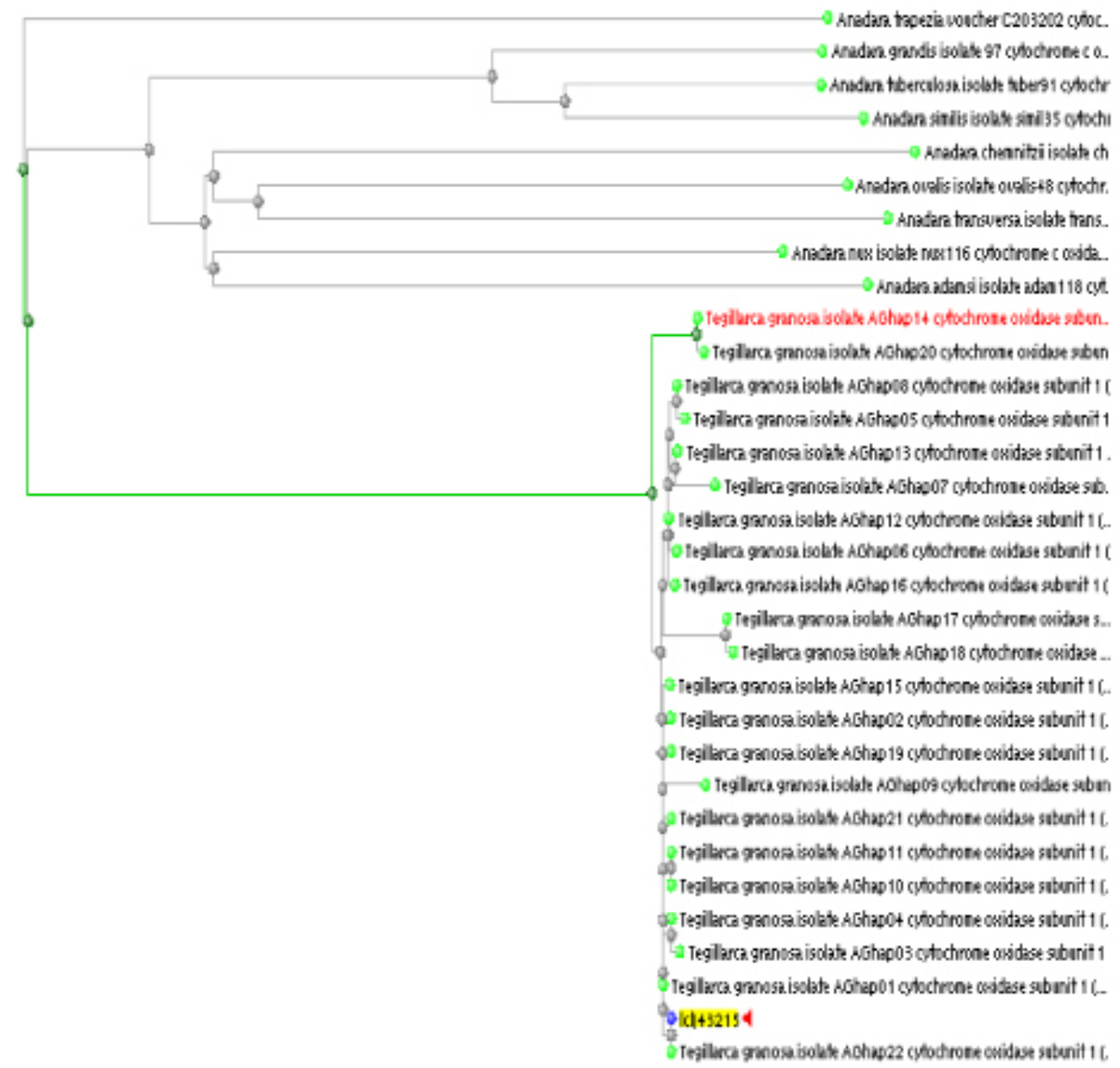

Figure 3. Phylogenetic tree of the cockle species analyzed as deduced from their COI gene sequences using the neighbor-joining phylogenetic-inference method. 


\section{DISCUSSION}

The presence of conserved regions in the mitochondrial genome is often utilized, particularly in phylogenetic studies ranging from parasites (Gibson et al., 2005) to fish (Abbasi et al., 2007). According to Remigio and Hebert (2003), shellfish identification using the conserved regions of a sequence is remarkable especially with the COI gene because it enables the recovery of shallow divergences and more robust estimates of shellfish relationships. The results of their study also suggested that COI sequences are well suited to give an indication of shifts in rates of molecular diversity as well as evidence of molecular evolution. The $\mathrm{COI}$ sequences have been used to characterize and infer phylogenies across vertebrates and invertebrates. However, in order to assess individuals that are closely related to each other, microsatellites should be employed. The studies of Canapa et al. (1999) on bivalves and Yoon and Kim (2005) on gastropods also supported the utilization of mtDNA, which includes both conserved and variable regions for phylogenetic investigations.

In order to estimate the time of divergence of T. granosa from the other closely related species, the COI sequence of $T$. granosa was aligned with sequences of related species deposited in GenBank. This analysis revealed that it had a moderate percentage of intrageneric similarity with other species found in South America, Caribbean and Australia ( $\approx 77 \%)$. Thus, evolutionary separation of T. granosa from its Australian as well as South American and Caribbean relatives could be assumed to have occurred at about the same time. However, when the sequence of $A$. grandis from Colombia was "blasted" with the sequences of the other species, it was found to be more related to the other South American species such as A. tuberculosa, A. similis and A. chemnitzii from Costa Rica and Ecuador (88-100\%) than to A. granosa from Peninsular Malaysia and A. trapezia from Australia. Cunningham (2008) stated in his study done on Littorina littorea in North America that new alleles only arose 20 kya. Based on this piece of information by Cunningham (2008), the South American species are estimated to have diverged from each other less than $240 \mathrm{kya}$. On the other hand, since T. granosa diverged by $23 \%$ from its South American relatives, it can be estimated that the Malaysian species evolved from the rest, including the Australian species about 460 kya.

A study conducted by Benson et al. (2001) on the green mussel (Perna viridis) found in Tampa Bay, Florida, also had a similarity of $78.2-99.5 \%$ to the $P$. viridis found in its native country, Trinidad. They discussed that the larvae of the species were probably entrained in ship ballast water. The conducive environments, which include the right temperature and the right substrates, contributed to their successful reproduction in Tampa Bay. Continued studies carried out by Fajans et al. (2004) three years after the first study had been done showed that the species had moved southward establishing new populations in Florida and Georgia. This finding shows how a closely related species can be found across large geographical distances, thrive and, to some extent, evolve over time to adapt to their surroundings.

The results of this study are beneficial in terms of identifying and classifying the cockles. Many times, the identification of specimens based on just the species' morphological attributes is inaccurate, leading to wrong conclusions in breeding and harvesting the cockles. Wang et al. (2008) used the fragments of the COI gene to classify the oysters in China using samples found in the Yangtze River. This study was able to distinguish the small oysters found in intertidal rocks as Crassostrea gigas, not $C$. piculata as widely assumed. They state that the small irregular shell characteristics are reflections of the stressful intertidal environment 
they inhabit and not reliable characters for classification. Therefore, their study highlighted the need for reclassifying oysters of China with molecular data to facilitate sampling activities.

This study serves as a basis for future studies possibly involving the conservation and management of the species. Phylogenies are powerful in drawing inferences from the structure of the tree, which can then be used to build hypotheses and models of important events in history. The relationships established by phylogenetic trees describe the species' evolutionary history and, hence, the historical relationships among lineages or organisms or their parts, such as genes.

\section{REFERENCES}

Abbasi AA, Paparidis Z, Malik S, Goode DK, et al. (2007). Human GLI3 intragenic conserved non-coding sequences are tissue-specific enhancers. PLoS One 2: e366.

Banks SC, Piggott MP, Raftos DA and Beheregaray LB (2006). Microsatellites markers for the Sydney rock oyster, Saccostrea glomerata, a commercially important bivalve in southeastern Australia. Mol. Ecol. Notes 6: 856-858.

Benson AJ, Merelli DC, Frischer ME, Danforth JM, et al. (2001). Establishment of the green mussel, Perna viridis (Linnaeus 1758), (Mollusca: Mytilidae) on the west coast of Florida. J. Shellfish Res. 20: 21-29.

Canapa A, Marota I, Rollo F and Olmo E (1999). The small-subunit rRNA gene sequences of venerids and the phylogeny of Bivalvia. J. Mol. Evol. 48: 463-468.

Colgan DJ, Ponder WF, Beacham E and Macaranas JM (2003). Molecular phylogenetic studies of Gastropoda based on six gene segments representing coding or non-coding and mitochondrial or nuclear DNA. Moll. Res. 23: 123-148.

Cunningham CW (2008). How to use genetic data to distinguish between natural and human-mediated introduction of Littorina littorea to North America. Biol. Invasions 10: 1-6.

Doadrio I and Dominguez O (2004). Phylogenetic relationships within the fish family Goodeidae based on cytochrome b sequence data. Mol. Phylogenet. Evol. 31: 416-430.

Fajans JS, Baker P, Baker S and Phlips E (2004). Biology, Ecology, and Physiology of the Non-indigenous Asian Green Mussel, Perna viridis (Mytilidae), in the Southeastern United States. 70th Annual Meeting, American Malacological Society, Sanibul Island, Florida.

FAO (Food and Agricultural Organization) (2006). Basic Bivalve Biology: Taxonomy, Anatomy and Life History. Food and Agricultural Organization of the United Nation. Available at [http://www.fao.org/docrep/007/y5720e/y5720e07. htm\#TopOfPage]. Accessed January 12, 2008.

Gibson WC, Lom J, Ferris VR and Hamilton PB (2005). Phylogenetic analysis of freshwater fish trypanosomes from Europe using ssu rRNA gene sequences and random amplification of polymorphic DNA. Parasitology 130: 405-412.

Ng FO (1986). Growth and Mortality of the Malaysian Cockle (Anadara granosa L.) Under Commercial Culture Analysis Through Length Frequency Data. Bay of Bengal Programme. Fisheries Research Institute Glugor, Malaysia.

Pathansali D (1963). Notes on the biology of the cockle, Anadara granosa L. Proc. Indo-Pacific Fish. Counc. 11: 84-98.

Pathansali D and Soong MK (1958). Some aspects of cockle (Anadara granosa L.) culture in Malaysia. Proc. Indo-Pacific Fish Counc. 8: 26-31.

Pawiro S (2006). Regional Review on Marine Aquaculture Products Demand, Trades and Markets. INFOFISH, Guangzhou, 1-26.

Provan J, Wattier RA and Maggs CA (2005). Phylogeographic analysis of the red seaweed Palmaria palmata reveals a Pleistocene marine glacial refugium in the English Channel. Mol. Ecol. 14: 793-803.

Remigio EA and Hebert PD (2003). Testing the utility of partial COI sequences for phylogenetic estimates of gastropod relationships. Mol. Phylogenet. Evol. 29: 641-647.

Sugiyama S, Staples D and Smith SF (2004). Status and Potential of Fisheries and Aquaculture in Asia and the Pacific. Asia Pacific Fishery Commission, Bangkok.

Tamura K, Dudley J, Nei M and Kumar S (2007). MEGA4: molecular evolutionary genetics analysis (MEGA) software version 4.0. Mol. Biol. Evol. 24: 1596-1599.

Wang H, Zhang G, Liu X and Guo X (2008). Classification of common oysters from North China. J. Shellfish Res. 27: 495-503.

Yoon SH and Kim W (2005). Phylogenetic relationships among six vetigastropod subgroups (Mollusca, Gastropoda) based on 18S rDNA sequences. Mol. Cells 19: 283-288. 